\title{
Genotypic effect of ahFAD2 on fatty acid profiles in six segregating peanut (Arachis hypogaea $\mathrm{L}$ ) populations
}

\author{
Noelle A Barkley ${ }^{1 *}$, Thomas G Isleib², Ming Li Wang ${ }^{1}$ and Roy N Pittman ${ }^{1}$
}

\begin{abstract}
Background: Fatty acid composition of oil extracted from peanut (Arachis hypogaea L.) seed is an important quality trait because it may affect the flavor and shelf life of resulting food products. In particular, a high ratio of oleic (C18:1) relative to linoleic (C18:2) fatty acid $(O / L \geq 10)$ results in a longer shelf life. Previous reports suggest that the high oleic ( $80 \%)$ trait was controlled by recessive alleles of ahFAD2A and ahFAD2B, the former of which is thought to have a high frequency in US runner- and virginia-type cultivars. Functional mutations, G448A in ahFAD2A and 442 ins A in ahFAD2B eliminate or knock down desaturase activity and have been demonstrated to produce peanut oil with high O/L ratios. In order to employ marker assisted selection (MAS) to select a high oleic disease resistant peanut and to evaluate genotypic and phenotypic variation, crosses were made between high oleic ( $80 \%)$ and normal oleic ( 50\%) peanuts to produce segregating populations.

Results: A total of $539 \mathrm{~F}_{2}$ progenies were randomly selected to empirically determine each ahFAD2 genotype and the resulting fatty acid composition. Five of the six crosses segregated for the high oleic trait in a digenic fashion. The remaining cross was consistent with monogenic segregation because both parental genotypes were fixed for the ahFAD2A mutation. Segregation distortion was significant in ahFAD2A in one cross; however, the remaining crosses showed no distortion. Quantitative analyses revealed that dominance was incomplete for the wild type allele of ahFAD2, and both loci showed significant additive effects. Oleic and linoleic acid displayed five unique phenotypes, based on the number of ahFAD2 mutant alleles. Further, the ahFAD2 loci did exhibit pleiotropic interactions with palmitic (C16:0), oleic (C18:1), linoleic (C18:2) acids and the O/L ratio. Fatty acid levels in these progeny were affected by the parental genotype suggesting that other genes also influence fatty acid composition in peanut. As far as the authors are aware, this is the first study in which all of the nine possible ahFAD2 genotypes were quantitatively measured.

Conclusions: The inheritance of the high oleic trait initially was suggested to be controlled by dominant gene action from two homoeologous genes (ahFAD2A and ahFAD2B) exhibiting complete recessivity. Analyzing the ahFAD2 genotypes and fatty acid compositions of these segregating peanut populations clearly demonstrated that the fatty acid contents are quantitative in nature although much of the variability in the predominant fatty acids (oleic, linoleic, and palmitic) is controlled by only two loci.
\end{abstract}

Keywords: Real-time PCR, Gas chromatography, ahFAD2, High oleic peanuts, Fatty acids, Segregation ratios

\footnotetext{
* Correspondence: Elle.Barkley@ars.usda.gov

${ }^{1}$ USDA ARS Plant Germplasm Resources Conservation Unit, 1109 Experiment

Street, Griffin, GA 30223, USA

Full list of author information is available at the end of the article
} 


\section{Background}

Peanut (Arachis hypogaea L., $2 n=4 x=40$ ) is a major oilseed crop worldwide. Regular dietary intake of its seeds provides a significant source of protein, folate, tocopherol, phytosterols, polyphenolics such as resveratrol, fiber, and edible oil. Regular consumption of peanuts has been demonstrated to have positive impacts on human health [1-3]. Chemical and epidemiological studies suggest that the nutritional properties of peanuts are favorable due to the fatty acid profiles (containing a minimum of $40 \%$ monounsaturated fatty acids), a high quality protein ratio score, and a source of naturally occurring folate [4]. A diet rich in monounsaturated fats containing high levels of fatty acids such as oleic acid (C18:1) has been associated with a reduction in systolic blood pressure [5], reduction of triacylglycerol [6], guarding low density lipoproteins (LDL) from oxidative modification [7], reduction of LDL and total cholesterol in hypercholesterolics [8], helping maintain good cholesterol levels known as high density lipoproteins (HDL), reduction of blood glucose levels in type II diabetes [9], and slowing down atherosclerosis [10].

Cultivated peanut is an allotetraploid and typically contains about $50 \%$ oil in the seeds. The majority $(\sim 80-$ $90 \%)$ of the extracted oil is composed of three primary fatty acids: palmitic (C16:0), oleic (C18:1), and linoleic (C18:2). The flavor, stability, shelf life, and nutritional quality of peanut and peanut products are dependent on the fatty acid composition (ratio of saturated, monounsaturated, and polyunsaturated lipids) of the extracted oil [11-13]. All oils are prone to oxidation over time, which leads to noxious odors and off flavors in stored peanut products. Further, oxidized lipids have been associated with atherosclerosis [14]. Oxidative rancidity is more prevalent among oils with high levels of polyunsaturated fatty acids due to the carbon double bonds that degrade over time producing acids, aldehydes, ketones and hydrocarbons [12]. Peanut that has a high percentage of oleic acid (monounsaturated $\omega-9$ fatty acid) and a low percentage of linoleic acid (polyunsaturated $\omega-6$ fatty acid) in the oil is less susceptible to rancidification which results in a longer shelf life for stored food products. Therefore, an emphasis from manufacturers and consumers has been placed on breeding peanut with high oleic acid and low linoleic acid.

Due to the efforts of the peanut breeding program in Florida in the 1980s, the first high oleic peanuts F435-2-1 and F435-2-2 were identified which had oleic levels ( $\sim 80 \%)$ comparable to that found in olive (Olea europaea L.) oil [15]. The high oleic acid seed oil trait in peanut (Arachis hypogaea L.) was originally designated $O l_{1}-o l_{1}$ and $\mathrm{Ol}_{2}-\mathrm{Ol}_{2}$ by Moore and Knauft [12]. The associations of $o l_{1}$ and $o l_{2}$ with the A and B genomes of Arachis hypogaea were not specified in the genes' original descriptions, but more recent molecular literature renames the loci $a h F A D 2 A$ and $a h F A D 2 B$. The inheritance of this desirable phenotype was later demonstrated to be controlled by two key homozygous recessive mutations in two homoeologs ahFAD2A and $a h F A D 2 B$, which encode microsomal oleoyl-PC desaturase, also known as $\Delta^{12}$ fatty acid desaturase $[12,13,16,17]$. Microsomal oleoylPC desaturases are responsible for catalyzing the conversion of oleate to linoleate [18] by the addition of a second double bond in the hydrocarbon chain which generates a polyunsaturated fatty acid from a monounsaturated fatty acid [19]. The mutations necessary for the high oleic phenotype found in these homoeologous genes, G448A (D150N) in ahFAD2A and 442insA in $a h F A D 2 B$, were shown to result in a loss of functional enzyme activity or significantly reduced mRNA transcript levels, respectively $[13,16,20]$. Both of the mutations (G448A and 442insA) in ahFAD2 affect the histidine motifs which are involved in the metal ion complex required for oxygen reduction [10,20]. Homozygous recessive mutations in both ahFAD2A and ahFAD2B (G448A and 442insA) are necessary for the high oleate phenotype; whereas, the normal oleate phenotype can be produced from a single homoeolog expressing a functional enzyme.

Studies following the discovery of the F435 high oleic peanuts also established that the trait segregated either in a digenic (15:1) or monogenic (3:1) fashion now known to be dependent on the normal oleic parental genotype $\left(\mathrm{ol}_{1} \mathrm{ol}_{1} \mathrm{Ol}_{2} \mathrm{Ol}_{2}\right.$ or $\left.\mathrm{Ol}_{1} \mathrm{Ol}_{1} \mathrm{Ol}_{2} \mathrm{Ol}_{2}\right)$ [12,16]. In most normaloleic U.S. runner- and virginia-type cultivars (predominantly $A$. hypogaea subsp. hypogaea var. hypogaea), one of the mutant alleles, ahFAD2A, often is fixed in the homozygous state, so that the high-oleic characteristic behaves as if controlled by a single gene pair. However, López et al. (2001) found somewhat more complex inheritance of the trait in crosses involving Spanish-type (A. hypogaea subsp. fastigiata Waldron var. vulgaris Harz) parents [21] in that some of the populations did not conform to monogenic or digenic segregation patterns.

Although numerous high oleic cultivars have been developed whose pedigrees include F435 as the high oleic donor, elite high oleic cultivars are still needed to thwart disease and abiotic challenges that exists in different environments [22]. Due to shelf life stability and health benefits, some countries (i.e.- Australia, Argentina, South Africa, Israel) are mostly or solely producing high oleic peanut products for consumption. Recently, efforts have been placed on producing high oleic peanuts with enhanced introgressed traits. Breeding multiple traits of interest, such as nematode resistance or other quality traits, into high oleic cultivars can be time consuming due to the generation time, phenotyping for the traits of interest, and maintaining large populations that are needed to obtain desired trait stacking. 
One of the main hurdles of breeding programs is purging unwanted phenotypes and genotypes from the segregating populations in early stages and rapidly identifying the trait(s) of interest. This can potentially be overcome by selecting individuals with desired genotypes at key loci by using molecular markers, a process known as marker-assisted selection (MAS). This is most efficient if heterozygous and homozygous states can be distinguished at all the loci of interest. Previously, real-time PCR assays have been developed to genotype peanuts for the ahFAD2 alleles [23,24] that can indeed detect all of the nine possible genotypes produced in segregating populations. Therefore, the objectives of this research were to (a) to implement ahFAD2 and nematode resistance markers in MAS for the development of a high oleic nematode resistant peanut lines, (b) determine the ahFAD2 genotypes and fatty acid profiles in segregating peanut populations to establish a link between each genotype and the resulting fatty acid composition, and (c) determine ahFAD2 gene action on fatty acid composition by variance analysis.

\section{Results \& discussion}

\section{Fatty acid composition}

Fatty acid profiles were collected on all of the parents and $539 \mathrm{~F}_{2}$ progeny produced from six crosses (Figure 1). Fitted curves were either normally distributed (C16:0, C22:0, C24:0), skewed (C18:0), or multimodal (C18:1, C18:2). No curves were generated for arachidic (20:0) or
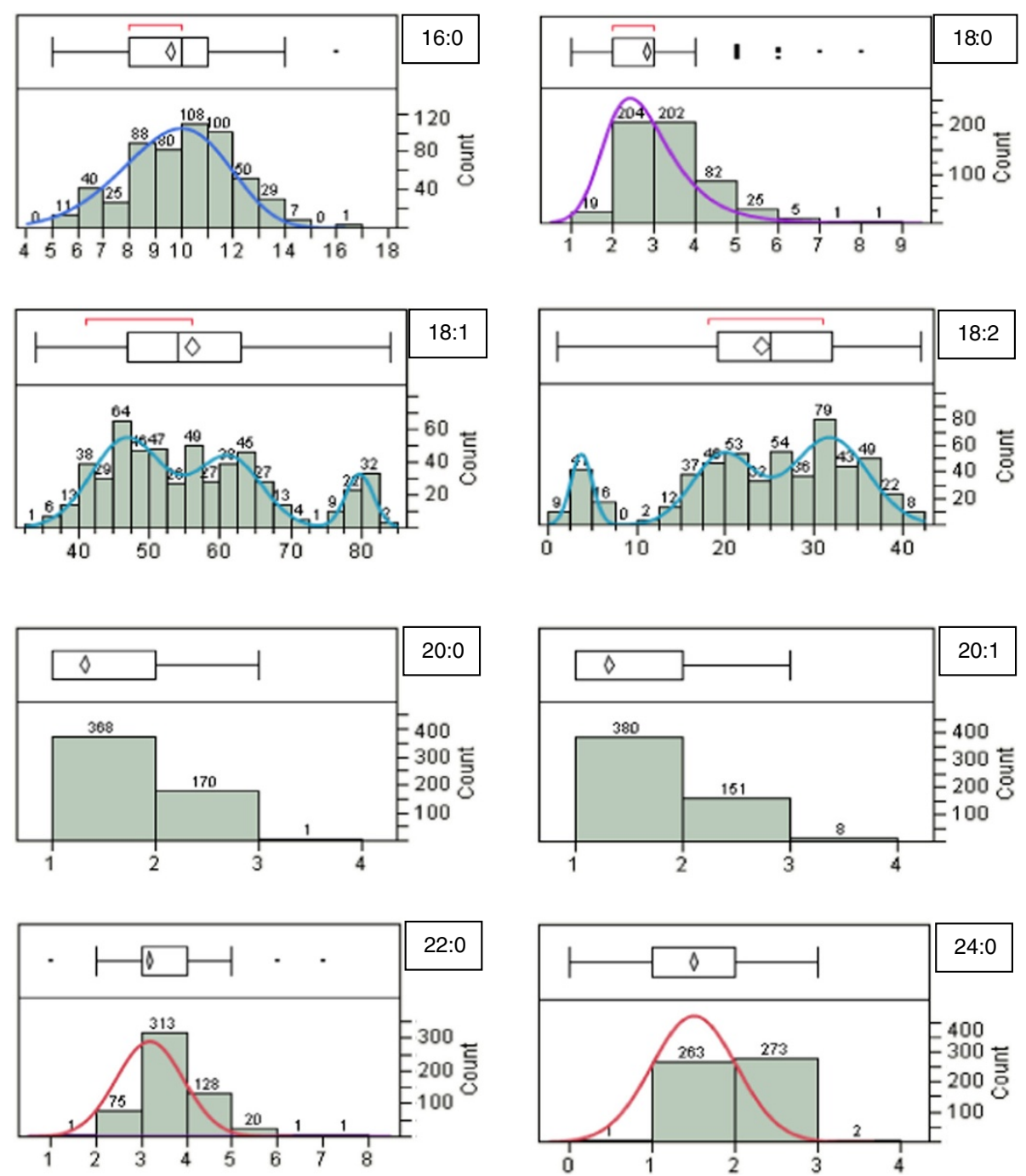

Figure 1 Histograms of the frequency distribution of the eight collected fatty acids from all six populations. (Fatty acid values were rounded to the nearest whole number). Ten different continuous fit curves were tested for each histogram and the best fit based on Akaike's Information Criterion (AIC) was chosen for each histogram. The $x$-axis shows the range in percentage of each fatty acid collected and the $y$-axis represents the number of individuals in the $F_{2}$ population. 
gadoleic (20:1) fatty acids because the majority of the $F_{2}$ progeny contained only $1-3 \%$ of these fatty acids. Originally, fatty acids in peanut were suggested to be under polygenic control until the discovery and elucidation of the high oleic trait [25]. Later, the inheritance of the high oleic trait initially was suggested to be controlled by dominant gene action from two homoeologous genes (ahFAD2A and $a h F A D 2 B$ ) exhibiting complete recessivity $[12,13]$. Once the large effects of $a h F A D 2 A$ and $a h F A D 2 B$ were identified, the remaining phenotypic variation must be ascribed to the effects of the environment and genes with small cumulative effects. Due to the continuous variation observed in this data, fatty acid composition is likely to be polygenically inherited. This is consistent with a previous study which evaluated oleic and linoleic acid contents among progeny derived from backcrossing [25].

Significant correlations between oleic acid and other fatty acids commonly detected in peanut have been previously reported [11,25-27]. Therefore, pair-wise correlation coefficients were calculated among all the collected fatty acids to determine if these fatty acids vary together or independently in the entire population (Figure 2; Table 1). Pooling the fatty acid data from Crosses 17, 19, 21, 25, 27 , and 28 showed significant negative correlations between oleic acid and palmitic acid [16:0] $(r=-0.8945$, $\mathrm{P}<0.0001)$, as well as, oleic and linoleic acid [C18:2]
( $\mathrm{r}=-0.9922, \mathrm{P}<0.0001)$. A significant positive correlation was also revealed between oleic and gadoleic acid [C20:1] $(\mathrm{r}=0.5227, \mathrm{P}<0.0001)$. This suggests that the ahFAD2 genotype may influence the level of oleic, linoleic, palmitic, and gadoleic fatty acids. Furthermore, pleiotropic effects are involved in determining fatty acid composition. Arachidic (C20:0) and behenic (C22:0) fatty acids also correlated with oleic with statistical significance; however, the coefficient of determination $\left(\mathrm{r}^{2}\right)$, which reflects the percentage of variance in oleic acid that can be explained by the variance in another fatty acid, was less than or equal to $3.5 \%$. Pairwise correlations revealed that fatty acids besides oleic acid were also significantly correlated. Stearic acid (C18:0) was positively and negatively correlated, respectively with arachidic acid [C20:0] ( $\mathrm{r}=0.8962$; $\mathrm{P}<0.0001)$ and gadoleic acid $[\mathrm{C} 20: 1] \quad(\mathrm{r}=-0.5942$, $\mathrm{P}<0.0001)$. Lignoceric acid (C24:0) was positively correlated with gadoleic $[\mathrm{C} 20: 1](\mathrm{r}=0.6881, \mathrm{P}<0.0001)$ and behenic $[\mathrm{C} 22: 0](\mathrm{r}=0.6657, \mathrm{P}<0.0001)$ fatty acids.

\section{ahFAD2 Genotypes in segregating peanut populations}

The parents, $\mathrm{F}_{1}$ 's and $539 \mathrm{~F}_{2}$ progeny were all genotyped for $a h F A D 2 A$ and $a h F A D 2 B$ in order to empirically determine a fatty acid profile for each $a h F A D 2$ genotype. All possible $a h F A D 2$ genotypes were detected in the larger populations $(17,19,25, \& 28)$. Only seven (Cross 21$)$

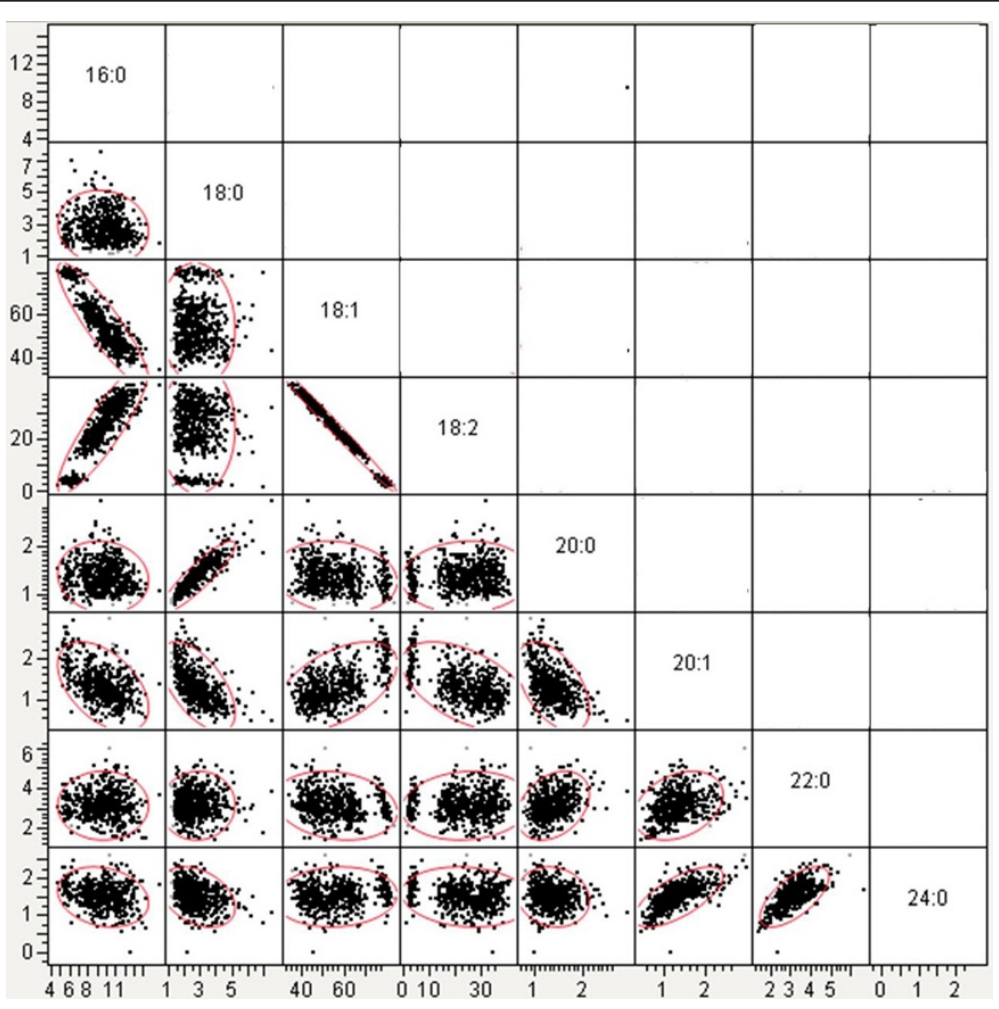

Figure 2 Pairwise comparisons of the correlations among the eight collected fatty acids. 
Table 1 Pairwise correlations among the eight collected fatty acids

\begin{tabular}{|c|c|c|c|c|c|c|c|c|}
\hline & $16: 0$ & $18: 0$ & $18: 1$ & $18: 2$ & $20: 0$ & $20: 1$ & $22: 0$ & $24: 0$ \\
\hline $16: 0$ & 1.0000 & & & & & & & \\
\hline \multirow[t]{2}{*}{$18: 0$} & -0.0923 & 1.0000 & & & & & & \\
\hline & $P=0.0322$ & & & & & & & \\
\hline \multirow[t]{2}{*}{$18: 1$} & -0.8945 & -0.0710 & 1.0000 & & & & & \\
\hline & $P<0.0001$ & $P=0.0996$ & & & & & & \\
\hline \multirow[t]{2}{*}{$18: 2$} & 0.8857 & 0.0134 & -0.9922 & 1.0000 & & & & \\
\hline & $P<0.0001$ & ns & $P<0.0001$ & & & & & \\
\hline \multirow[t]{2}{*}{$20: 0$} & -0.0909 & 0.8962 & -0.1347 & 0.0624 & 1.0000 & & & \\
\hline & $P=0.0349$ & $P<0.0001$ & $P=0.0017$ & ns & & & & \\
\hline \multirow[t]{2}{*}{$20: 1$} & -0.4869 & -0.5942 & 0.5227 & -0.5285 & -0.5060 & 1.0000 & & \\
\hline & $P<0.0001$ & $P<0.0001$ & $P<0.0001$ & $P<0.0001$ & $P<0.0001$ & & & \\
\hline \multirow[t]{2}{*}{$22: 0$} & 0.0006 & 0.0323 & -0.1885 & 0.1032 & 0.3298 & 0.3125 & 1.0000 & \\
\hline & ns & ns & $P<0.0001$ & $P=0.0165$ & $P<0.0001$ & $P<0.0001$ & & \\
\hline \multirow[t]{2}{*}{$24: 0$} & -0.2037 & -0.3561 & 0.0829 & -0.1264 & -0.1203 & 0.6881 & 0.6657 & 1.0000 \\
\hline & $P<0.0001$ & $P<0.0001$ & ns & $P=0.0033$ & $P=0.0052$ & $P<0.0001$ & $P<0.0001$ & \\
\hline
\end{tabular}

and eight (Cross 27) ahFAD2 genotypes were detected in the smaller populations (Additonal file 1: Table S1). Chi square analysis was employed to evaluate if the $\mathrm{F}_{2}$ progenies were segregating in a digenic $15: 1$ or mongenic $3: 1$ fashion for the high oleic phenotype (Table 2). Both of the parents of Cross 25 were determined by ahFAD2 genotyping to be fixed (homozygous recessive) for the $a h F A D 2 A$ mutation; whereas, the parents of the remaining crosses were homozygous wild type crossed by a high oleic genotype. Therefore, as expected, three of the four crosses with $125 \mathrm{~F}_{2}$ progeny were consistent with a $15: 1$ segregation ratio while cross 25 conformed to a 3:1 ratio. None of these crosses had segregation ratios that did not fit the expected ratios as seen in a previous study [21]. Further, segregation distortion from Mendelian expectations was evaluated for all the $F_{2}$ progenies and for each individual cross (Table 3). Overall, segregation distortion was a relatively minor effect in that only a single cross (Cross 17) showed statistically significant $(\mathrm{P} \leq 0.05)$ distortion at a single locus (ahFAD2A). Neither ahFAD2A nor $a h F A D 2 B$ was distorted in any of the other crosses or when evaluating the total population. Distortion in loci can be caused by differential representation of distorted genotypes in gametes prior to fertilization or viability differences in zygotes after fertilization [28]. Segregation distortion of molecular markers in cultivated peanut has been reported previously [29-31].

\section{Linking phenotypes and genotypes}

A broad range of oleic acid (C18:1) content was detected from the $a h F A D 2$ genotypes in the entire population varying from 34.15 to $84.10 \%$; whereas, linoleic acid (C18:2) ranged from 1.31 to $33.08 \%$ (Additional file 1:
Table S1, Figure 3). As expected, the lowest amount of oleic acid was found in homozygous dominant genotypes, while the highest amounts were in the homozygous recessive genotypes. The $\mathrm{O} / \mathrm{L}$ ratio varied from 0.85 to 61.28 . Palmitic acid ranged from 5.38 to $15.87 \%$; however, the high oleic lines contained significantly less palmitic acid than the normal oleic lines. Stearic acid ranged from 1.13 to $7.59 \%$ in the population. Arachidic acid (0.76-2.94\%), gadoleic acid (0.5-2.93\%), behenic (1.14-6.63\%) and lignoceric acid (0-2.74\%) contents were detected in these progenies; but, their percentages were fairly small compared to the other fatty acids. Although up to 12 fatty acids have been previously reported as detectable in peanuts, only three (palmitic, oleic, and linoleic) comprise the majority $(\sim 90 \%)$ of the fatty acids found in peanut oil $[12,15]$. This same trend was consistent with these populations. The percentage of the three predominant fatty acids (C16:0, C18:1, and C18:2) detected in the extracted oil in these populations ranged from 84 to $93.75 \%$.

Tukey's method was utilized to compare which ahFAD2 genotypes had significantly different means for each fatty acid collected in the entire population (Table 4). In the whole population, the mean values of stearic and behenic acids were not significantly different by genotype; but, the means of the remaining six fatty acids did vary by genotype. Comparing each of the nine genotypes detected along with their respective oleic acid mean demonstrated that as the number of mutant alleles increased so did the total oleic acid content. However, the oleic acid content of ahFAD2 genotypes with the same number of mutant alleles was not statistically different (Table 4). Therefore, the mean oleic values were 
Table 2 Segregation analysis of the high oleic trait

\begin{tabular}{|c|c|c|c|c|c|c|c|c|c|c|c|c|c|}
\hline $\begin{array}{l}\text { Cross } \\
\text { ID }\end{array}$ & Cross & $\begin{array}{l}\text { Range of } O / L \text { ratio } \\
\text { in the } F_{2} \text { progeny }\end{array}$ & $\begin{array}{l}\text { Observed } \\
\text { normal oleic }\end{array}$ & $\begin{array}{l}\text { Observed } \\
\text { high oleic }\end{array}$ & $\begin{array}{l}\text { Expected } \\
\text { normal }(15: 1)\end{array}$ & $\begin{array}{l}\text { Expected } \\
\text { high }(15: 1)\end{array}$ & $x^{2}(15: 1)$ & $\begin{array}{l}\text { Expected } \\
\text { normal }(9: 7)\end{array}$ & $\begin{array}{l}\text { Expected } \\
\text { high }(9: 7)\end{array}$ & $x^{2}(9: 7)$ & $\begin{array}{l}\text { Expected } \\
\text { normal }(3: 1)\end{array}$ & $\begin{array}{l}\text { Expected } \\
\text { high }(3: 1) \text { I }\end{array}$ & $\mathrm{x}^{2}(3: 1)$ \\
\hline 17 & $\begin{array}{l}\text { Florida } 07^{\mathrm{a}} / \\
\text { A. hypogaea } \\
\text { var. hirsuta }\end{array}$ & $0.85-43.58$ & 122 & 3 & 117.188 & 7.8125 & 2.54 & 70.3125 & 54.6875 & $85.18^{* * *}$ & 93.75 & 31.25 & $32.86^{* * *}$ \\
\hline 19 & $\begin{array}{l}\text { York/A. } \\
\text { hypogaea } \\
\text { var. peruviana }\end{array}$ & $0.93-61.28$ & 113 & 12 & 117.188 & 7.8125 & 1.86 & 70.3125 & 54.6875 & $57.86^{* * *}$ & 93.75 & 31.25 & $15.00^{* * *}$ \\
\hline 21 & $\begin{array}{l}\text { Chicoc/ } \\
\text { Florida } 07\end{array}$ & $0.85-4.72$ & 18 & 0 & 16.875 & 1.125 & 2.50 & 10.125 & 7.875 & $12.28^{* * *}$ & 13.5 & 4.5 & $4.74^{*}$ \\
\hline 25 & $\begin{array}{l}\text { Tifguard } / \\
\text { York }\end{array}$ & $1.14-37.61$ & 84 & 41 & 117.188 & 7.8125 & $145.88^{* * *}$ & 70.3125 & 54.6875 & $5.65^{*}$ & 93.75 & 31.25 & 3.65 \\
\hline 27 & $\begin{array}{l}\text { Florida } 07^{\mathrm{a}} \text { / } \\
\text { A. hypogaea } \\
\text { var. peruviana }\end{array}$ & $0.92-23.47$ & 20 & 1 & 19.6875 & 1.3125 & 0.54 & 11.8125 & 9.1875 & $11.44^{* * *}$ & 15.75 & 5.25 & 3.57 \\
\hline 28 & Chico ${ }^{c}$ /York & $0.92-39.47$ & 116 & 9 & 117.188 & 7.8125 & 0.06 & 70.3125 & 54.6875 & $66.38^{* * *}$ & 93.75 & 31.25 & $20.18^{* * *}$ \\
\hline
\end{tabular}


Table 3 Test for segregation distortion in ahFAD2

\begin{tabular}{|c|c|c|c|c|c|c|c|c|c|}
\hline $\begin{array}{l}\text { Cross } \\
\text { ID } \\
\end{array}$ & Cross & $\begin{array}{l}\text { Observed } \\
\mathrm{Ol}_{1} \mathrm{Ol}_{1}\end{array}$ & $\begin{array}{l}\text { Observed } \\
\mathrm{Ol}_{1} \mathrm{Ol}_{1}\end{array}$ & $\begin{array}{l}\text { Observed } \\
\mathrm{ol}_{1} \mathrm{Ol}_{1}\end{array}$ & $x^{2}$ & $\begin{array}{l}\text { Observed } \\
\mathrm{Ol}_{2} \mathrm{Ol}_{2}\end{array}$ & $\begin{array}{l}\text { Observed } \\
\mathrm{Ol}_{2} \mathrm{Ol}_{2}\end{array}$ & $\begin{array}{l}\text { Observed } \\
\mathrm{Ol}_{2} \mathrm{Ol}_{2}\end{array}$ & $x^{2}$ \\
\hline 17 & $\begin{array}{l}\text { Florida } 07^{\mathrm{a}} / \mathrm{A} \text {. hypogaea } \\
\text { var. hirsuta }\end{array}$ & 43 & 50 & 31 & $6.41^{*}$ & 37 & 61 & 24 & 2.79 \\
\hline 19 & $\begin{array}{l}\text { York/A. hypogaea var. } \\
\text { peruviana }\end{array}$ & 25 & 64 & 36 & 2.05 & 38 & 49 & 37 & 5.28 \\
\hline 21 & $\begin{array}{l}\text { Florida } 07^{\mathrm{a}} / \mathrm{A} \text {. hypogaea var. } \\
\text { peruviana }\end{array}$ & 3 & 13 & 2 & 4.25 & 6 & 6 & 6 & 1.14 \\
\hline 25 & Tifguard ${ }^{\mathrm{b}}$ /York & 0 & 0 & 125 & 0.00 & 24 & 60 & 41 & 4.72 \\
\hline 27 & Chico ${ }^{c} /$ Florida $07^{a}$ & 3 & 10 & 8 & 2.5 & 9 & 7 & 5 & 2.98 \\
\hline \multirow[t]{2}{*}{28} & Chico ${ }^{c}$ York & 36 & 59 & 30 & 0.93 & 37 & 62 & 26 & 1.94 \\
\hline & Total Population & 110 & 196 & 107 & 1.07 & 151 & 245 & 139 & 4.08 \\
\hline
\end{tabular}

$\mathrm{a}=[37]$.

$\mathrm{b}=[32]$.

$\mathrm{c}=[36]$.

$*^{* * *, * * *}=$ difference is statistically significant at $0.05,0.01$, and 0.001 probability level, respectively.

equivalent for the following genotypes $\mathrm{Ol}_{1} \mathrm{Ol}_{1} \mathrm{Ol}_{2} \mathrm{Ol}_{2}$, $\mathrm{ol}_{1} \mathrm{Ol}_{1} \mathrm{Ol}_{2} \mathrm{Ol}_{2}$, and $\mathrm{Ol}_{1} \mathrm{Ol}_{1} \mathrm{ol}_{2} \mathrm{Ol}_{2}$. This same trend was observed for linoleic acid. The mean values of oleic and linoleic fatty acids sorted by the nine possible genotypes were only significantly different in the population when the number of mutant or wild type alleles increased or decreased (Table 4). This analysis revealed a total of five distinct phenotypes for the oleic and linoleic trait based on having $0,1,2,3$, or 4 mutant alleles in the ahFAD2 genotype. This data suggests there is a dosage effect for the oleic and linoleic phenotypes in that as the number of mutant alleles increases the oleic acid content increases and the linoleic acid content decreases. Further, this data suggests that mutant alleles in the A genome do not have a bigger effect on oleic acid accumulation than the mutant alleles in the $\mathrm{B}$ genome or vice versa. The largest effect in boosting the oleic content was achieved by increasing the total number of mutant alleles in the progeny. A similar trend was also observed for palmitic acid except that only four distinct phenotypes were observed. The mean for palmitic acid produced from the wild type genotype $\left(\mathrm{Ol}_{1} \mathrm{Ol}_{1} \mathrm{Ol}_{2} \mathrm{Ol}_{2}\right)$ was not significantly different from the means of genotypes containing one ahFAD2 mutant allele $\left(\mathrm{Ol}_{1} \mathrm{Ol}_{1} \mathrm{Ol}_{2} \mathrm{Ol}_{2}\right.$ or $\left.\mathrm{Ol}_{1} \mathrm{Ol}_{1} \mathrm{Ol}_{2} \mathrm{Ol}_{2}\right)$. Nevertheless, as the number of mutant alleles $(2,3, \& 4)$ increased in the progeny, the means of palmitic acid grouped by genotype were significantly different.

ANOVA was employed on the combined data set of Crosses 17, 19, and 28 (Table 5). These three crosses were chosen for the analysis due to their large population sizes and because all nine genotypes were detected by ahFAD 2 genotyping. This data set exhibited significant effects from the background genotypes of the parents on most of the fatty acids, suggesting that other loci besides $a h F A D 2 A$ and $a h F A D 2 B$ are involved in the production of these fatty acids (Table 5). The ahFAD2 genotype also played a significant role in influencing levels of palmitic, oleic, linoleic, gadoleic acids, and the $\mathrm{O} / \mathrm{L}$ ratio $(\mathrm{P}<0.01)$ in these populations, suggesting a significant pleiotropic effect. The genotype influenced arachidic and lignoceric acid contents as well $(\mathrm{P}<0.05)$. The ahFAD2 genotype however, did not have any significant effect on stearic acid or behenic acid. These results were similar to a previously published report except that arachidic and lignoceric acids were previously not found to be affected by genotype [25]. Significant interactions between the ahFAD2A and $a h F A D 2 B$ loci were detected for palmitic, oleic, linoleic acids, and the $\mathrm{O} / \mathrm{L}$ ratio $(\mathrm{P}<$ 0.01 ), suggesting epistasis between these homoeologous genes. Further, significant additive and dominant affects were observed for both loci for all fatty acids except stearic, arachidic, behenic, and lignoceric acids. Due to the significant positive and negative additive and dominance estimates detected for most of the fatty acids collected, dominance appears to be incomplete for alleles of the ahFAD2 genes. Further, incomplete dominance was also apparent from the intermediate mean values of palmitic, oleic, and linoleic acid phenotypes of the heterozygous ahFAD2B $\left(\mathrm{ol}_{1} \mathrm{ol}_{1} \mathrm{Ol}_{2} \mathrm{Ol}_{2}\right)$ progenies in Cross 25 compared to the homozygous recessive and dominant genotypes (Additional file 1: Table S1, Figure 3).

\section{Nematode resistance in cross $\mathbf{2 5}$}

Root knot nematode [Meloidogyne arenaria (Neal) Chitwood race 1] causes significant economic loss to the southeastern USA peanut crop each year. Resistant peanut lines, such as 'Tifguard' [32], have been developed to resist infection and help prevent significant yield loss. Tifguard also has been demonstrated to carry field resistance to TSWV and was initially developed by crossing 'C-99R' [33] with 'COAN' [34]. The population was advanced via single seed descent then the resulting progenies were phenotyped [32]. Molecular markers were 

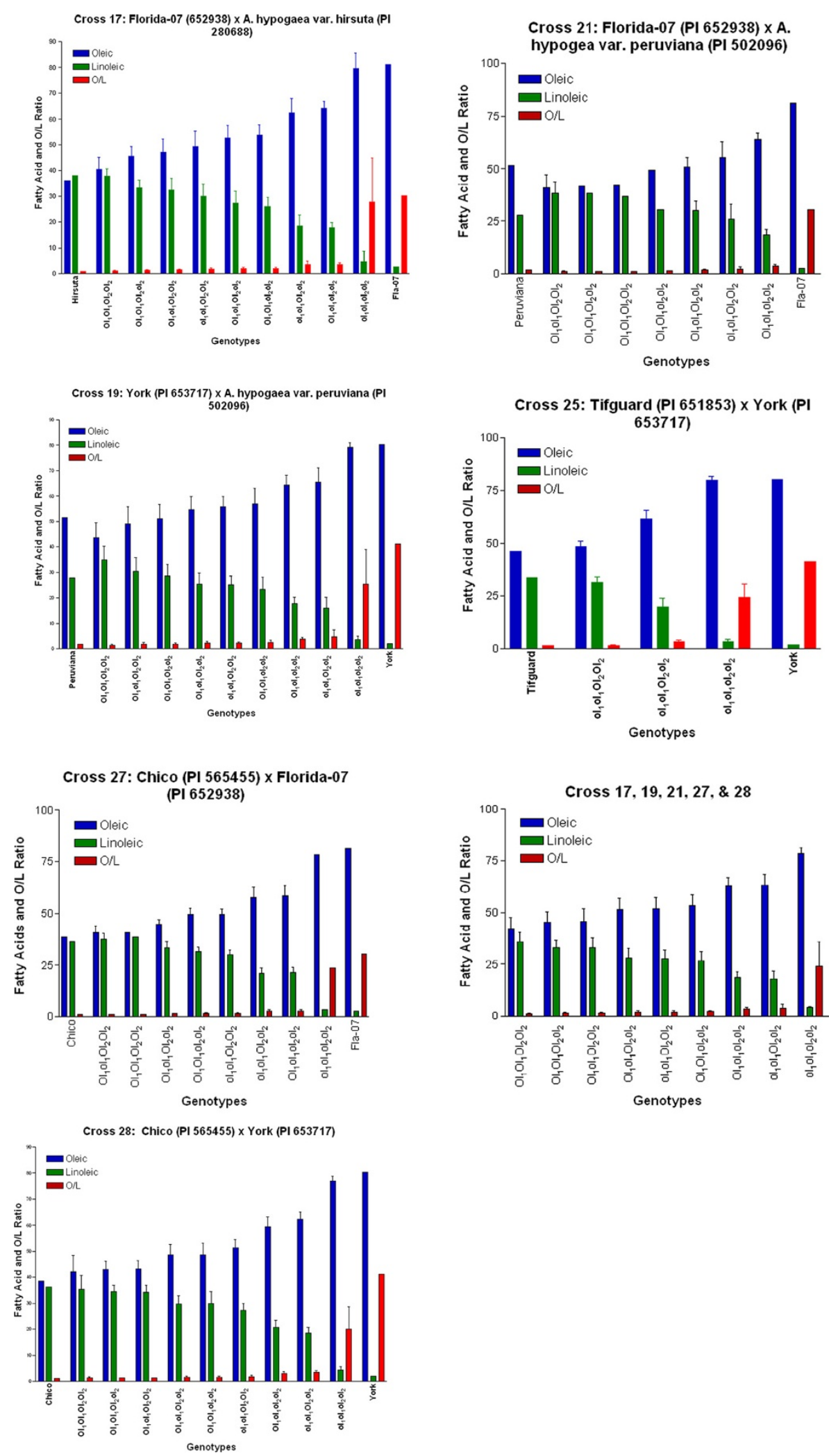

Figure 3 Mean oleic, linoleic, and O/L ratio of each genotype for each cross and all crosses pooled from the total population that segregated in a 15:1 fashion. Cross 25 segregating in a 3:1 fashion; whereas, the remaining crosses were consistent with 15:1 segregation. The high and normal oleic parent are also included. 
Table 4 The fatty acid mean comparison split into each of the genotypes detected from the six segregating populations

\begin{tabular}{|c|c|c|c|c|c|c|c|c|c|}
\hline Fatty acid & $F$ Ratio and $P$ value & Genotype & Mean & Tukey & Fatty acid & $F$ Ratio and $P$ value & Genotype & Mean & Tukey \\
\hline \multirow[t]{9}{*}{ Palmitic C16:0 } & \multirow[t]{9}{*}{$F=150 ; P<0.0001$} & $\mathrm{Ol}_{1} \mathrm{Ol}_{1} \mathrm{Ol}_{2} \mathrm{Ol}_{2}$ & 11.87 & $A$ & \multirow[t]{9}{*}{ Arachidic $20: 0$} & \multirow[t]{9}{*}{$F=2.39 ; P=0.0154$} & $\mathrm{Ol}_{1} \mathrm{Ol}_{1} \mathrm{Ol}_{2} \mathrm{Ol}_{2}$ & 1.42 & $A B$ \\
\hline & & $\mathrm{Ol}_{1} \mathrm{Ol}_{1} \mathrm{Ol}_{2} \mathrm{Ol}_{2}$ & 11.28 & A & & & $\mathrm{Ol}_{1} \mathrm{Ol}_{1} \mathrm{Ol}_{2} \mathrm{Ol}_{2}$ & 1.38 & $A B$ \\
\hline & & $\mathrm{Ol}_{1} \mathrm{Ol}_{1} \mathrm{Ol}_{2} \mathrm{Ol}_{2}$ & 11.23 & A & & & $\mathrm{Ol}_{1} \mathrm{Ol}_{1} \mathrm{Ol}_{2} \mathrm{Ol}_{2}$ & 1.44 & A \\
\hline & & $\mathrm{Ol}_{1} \mathrm{Ol}_{1} \mathrm{Ol}_{2} \mathrm{Ol}_{2}$ & 10.34 & B & & & $\mathrm{Ol}_{1} \mathrm{Ol}_{1} \mathrm{Ol}_{2} \mathrm{Ol}_{2}$ & 1.42 & A \\
\hline & & $\mathrm{Ol}_{1} \mathrm{Ol}_{1} \mathrm{Ol}_{2} \mathrm{Ol}_{2}$ & 10.35 & B & & & $\mathrm{Ol}_{1} \mathrm{Ol}_{1} \mathrm{Ol}_{2} \mathrm{Ol}_{2}$ & 1.32 & $A B$ \\
\hline & & $\mathrm{Ol}_{1} \mathrm{Ol}_{1} \mathrm{Ol}_{2} \mathrm{Ol}_{2}$ & 10.15 & B & & & $\mathrm{Ol}_{1} \mathrm{Ol}_{1} \mathrm{Ol}_{2} \mathrm{Ol}_{2}$ & 1.38 & $A B$ \\
\hline & & $\mathrm{Ol}_{1} \mathrm{Ol}_{1} \mathrm{Ol}_{2} \mathrm{Ol}_{2}$ & 8.84 & C & & & $\mathrm{Ol}_{1} \mathrm{Ol}_{1} \mathrm{Ol}_{2} \mathrm{Ol}_{2}$ & 1.24 & B \\
\hline & & $\mathrm{Ol}_{1} \mathrm{Ol}_{1} \mathrm{Ol}_{2} \mathrm{Ol}_{2}$ & 8.33 & C & & & $\mathrm{Ol}_{1} \mathrm{Ol}_{1} \mathrm{Ol}_{2} \mathrm{Ol}_{2}$ & 1.37 & $A B$ \\
\hline & & $\mathrm{Ol}_{1} \mathrm{Ol}_{1} \mathrm{Ol}_{2} \mathrm{Ol}_{2}$ & 6.15 & $\mathrm{D}$ & & & $\mathrm{Ol}_{1} \mathrm{Ol}_{1} \mathrm{Ol}_{2} \mathrm{Ol}_{2}$ & 1.30 & $A B$ \\
\hline \multirow[t]{9}{*}{ Stearic 18:0 } & \multirow[t]{9}{*}{$F=1.49 ; P=0.1560$} & $\mathrm{Ol}_{1} \mathrm{Ol}_{1} \mathrm{Ol}_{2} \mathrm{Ol}_{2}$ & 2.95 & A & \multirow[t]{9}{*}{ Gadoleic 20:1 } & \multirow[t]{9}{*}{$F=40.92 ; P<0.0001$} & $\mathrm{Ol}_{1} \mathrm{Ol}_{1} \mathrm{Ol}_{2} \mathrm{Ol}_{2}$ & 1.06 & $C$ \\
\hline & & $\mathrm{Ol}_{1} \mathrm{Ol}_{1} \mathrm{Ol}_{2} \mathrm{Ol}_{2}$ & 3.00 & A & & & $\mathrm{Ol}_{1} \mathrm{Ol}_{1} \mathrm{Ol}_{2} \mathrm{Ol}_{2}$ & 1.08 & C \\
\hline & & $\mathrm{Ol}_{1} \mathrm{Ol}_{1} \mathrm{Ol}_{2} \mathrm{O}_{2}$ & 2.97 & A & & & $\mathrm{Ol}_{1} \mathrm{Ol}_{1} \mathrm{Ol}_{2} \mathrm{Ol}_{2}$ & 1.14 & C \\
\hline & & $\mathrm{Ol}_{1} \mathrm{Ol}_{1} \mathrm{Ol}_{2} \mathrm{Ol}_{2}$ & 2.96 & A & & & $\mathrm{Ol}_{1} \mathrm{Ol}_{1} \mathrm{Ol}_{2} \mathrm{Ol}_{2}$ & 1.19 & C \\
\hline & & $\mathrm{Ol}_{1} \mathrm{Ol}_{1} \mathrm{Ol}_{2} \mathrm{Ol}_{2}$ & 2.66 & A & & & $\mathrm{Ol}_{1} \mathrm{Ol}_{1} \mathrm{Ol}_{2} \mathrm{Ol}_{2}$ & 1.30 & $\mathrm{BC}$ \\
\hline & & $\mathrm{Ol}_{1} \mathrm{Ol}_{1} \mathrm{Ol}_{2} \mathrm{Ol}_{2}$ & 2.82 & A & & & $\mathrm{Ol}_{1} \mathrm{Ol}_{1} \mathrm{Ol}_{2} \mathrm{Ol}_{2}$ & 1.24 & C \\
\hline & & $\mathrm{Ol}_{1} \mathrm{Ol}_{1} \mathrm{Ol}_{2} \mathrm{Ol}_{2}$ & 2.53 & A & & & $\mathrm{Ol}_{1} \mathrm{Ol}_{1} \mathrm{Ol}_{2} \mathrm{Ol}_{2}$ & 1.44 & B \\
\hline & & $\mathrm{Ol}_{1} \mathrm{Ol}_{1} \mathrm{Ol}_{2} \mathrm{Ol}_{2}$ & 2.76 & A & & & $\mathrm{Ol}_{1} \mathrm{Ol}_{1} \mathrm{Ol}_{2} \mathrm{Ol}_{2}$ & 1.47 & B \\
\hline & & $\mathrm{Ol}_{1} \mathrm{Ol}_{1} \mathrm{Ol}_{2} \mathrm{Ol}_{2}$ & 2.69 & A & & & $\mathrm{Ol}_{1} \mathrm{Ol}_{1} \mathrm{Ol}_{2} \mathrm{Ol}_{2}$ & 1.95 & A \\
\hline \multirow[t]{9}{*}{ Oleic 18:1 } & \multirow[t]{9}{*}{$F=351 ; P<0.0001$} & $\mathrm{Ol}_{1} \mathrm{Ol}_{1} \mathrm{Ol}_{2} \mathrm{Ol}_{2}$ & 42.02 & $E$ & \multirow[t]{9}{*}{ Behenic 22:0 } & \multirow[t]{9}{*}{$F=0.83 ; P=0.5701$} & $\mathrm{Ol}_{1} \mathrm{Ol}_{1} \mathrm{Ol}_{2} \mathrm{Ol}_{2}$ & 3.21 & A \\
\hline & & $\mathrm{Ol}_{1} \mathrm{Ol}_{1} \mathrm{Ol}_{2} \mathrm{Ol}_{2}$ & 45.83 & $\mathrm{D}$ & & & $\mathrm{Ol}_{1} \mathrm{Ol}_{1} \mathrm{Ol}_{2} \mathrm{Ol}_{2}$ & 3.07 & A \\
\hline & & $\mathrm{Ol}_{1} \mathrm{Ol}_{1} \mathrm{Ol}_{2} \mathrm{Ol}_{2}$ & 45.50 & $\mathrm{D}$ & & & $\mathrm{Ol}_{1} \mathrm{Ol}_{1} \mathrm{Ol}_{2} \mathrm{Ol}_{2}$ & 3.28 & A \\
\hline & & $\mathrm{Ol}_{1} \mathrm{Ol}_{1} \mathrm{Ol}_{2} \mathrm{Ol}_{2}$ & 51.43 & C & & & $\mathrm{Ol}_{1} \mathrm{Ol}_{1} \mathrm{Ol}_{2} \mathrm{Ol}_{2}$ & 3.25 & A \\
\hline & & $\mathrm{Ol}_{1} \mathrm{Ol}_{1} \mathrm{Ol}_{2} \mathrm{Ol}_{2}$ & 53.28 & C & & & $\mathrm{Ol}_{1} \mathrm{Ol}_{1} \mathrm{Ol}_{2} \mathrm{Ol}_{2}$ & 3.11 & A \\
\hline & & $\mathrm{Ol}_{1} \mathrm{Ol}_{1} \mathrm{Ol}_{2} \mathrm{Ol}_{2}$ & 50.60 & C & & & $\mathrm{Ol}_{1} \mathrm{Ol}_{1} \mathrm{Ol}_{2} \mathrm{Ol}_{2}$ & 3.18 & A \\
\hline & & $\mathrm{Ol}_{1} \mathrm{Ol}_{1} \mathrm{Ol}_{2} \mathrm{Ol}_{2}$ & 62.70 & B & & & $\mathrm{Ol}_{1} \mathrm{Ol}_{1} \mathrm{Ol}_{2} \mathrm{Ol}_{2}$ & 3.03 & A \\
\hline & & $\mathrm{Ol}_{1} \mathrm{Ol}_{1} \mathrm{Ol}_{2} \mathrm{Ol}_{2}$ & 63.14 & B & & & $\mathrm{Ol}_{1} \mathrm{Ol}_{1} \mathrm{Ol}_{2} \mathrm{Ol}_{2}$ & 3.18 & A \\
\hline & & $\mathrm{Ol}_{1} \mathrm{Ol}_{1} \mathrm{Ol}_{2} \mathrm{Ol}_{2}$ & 79.44 & A & & & $\mathrm{Ol}_{1} \mathrm{Ol}_{1} \mathrm{Ol}_{2} \mathrm{Ol}_{2}$ & 3.08 & A \\
\hline \multirow[t]{9}{*}{ Linoleic 18:2 } & \multirow[t]{9}{*}{$F=383 ; P<0.0001$} & $\mathrm{Ol}_{1} \mathrm{Ol}_{1} \mathrm{Ol}_{2} \mathrm{Ol}_{2}$ & 36.05 & A & \multirow[t]{9}{*}{ Lignoceric 24:0 } & \multirow[t]{9}{*}{$F=5.00 ; P<0.0001$} & $\mathrm{Ol}_{1} \mathrm{Ol}_{1} \mathrm{Ol}_{2} \mathrm{Ol}_{2}$ & 1.41 & $B C$ \\
\hline & & $\mathrm{Ol}_{1} \mathrm{Ol}_{1} \mathrm{Ol}_{2} \mathrm{Ol}_{2}$ & 32.96 & B & & & $\mathrm{Ol}_{1} \mathrm{Ol}_{1} \mathrm{Ol}_{2} \mathrm{Ol}_{2}$ & 1.40 & C \\
\hline & & $\mathrm{Ol}_{1} \mathrm{Ol}_{1} \mathrm{Ol}_{2} \mathrm{Ol}_{2}$ & 32.97 & B & & & $\mathrm{Ol}_{1} \mathrm{Ol}_{1} \mathrm{Ol}_{2} \mathrm{Ol}_{2}$ & 1.47 & $B C$ \\
\hline & & $\mathrm{Ol}_{1} \mathrm{Ol}_{1} \mathrm{Ol}_{2} \mathrm{Ol}_{2}$ & 27.98 & C & & & $\mathrm{Ol}_{1} \mathrm{Ol}_{1} \mathrm{Ol}_{2} \mathrm{Ol}_{2}$ & 1.44 & C \\
\hline & & $\mathrm{Ol}_{1} \mathrm{Ol}_{1} \mathrm{Ol}_{2} \mathrm{Ol}_{2}$ & 26.48 & C & & & $\mathrm{Ol}_{1} \mathrm{Ol}_{1} \mathrm{Ol}_{2} \mathrm{Ol}_{2}$ & 1.50 & $A B C$ \\
\hline & & $\mathrm{Ol}_{1} \mathrm{Ol}_{1} \mathrm{Ol}_{2} \mathrm{Ol}_{2}$ & 29.16 & C & & & $\mathrm{Ol}_{1} \mathrm{Ol}_{1} \mathrm{Ol}_{2} \mathrm{Ol}_{2}$ & 1.44 & $\mathrm{BC}$ \\
\hline & & $\mathrm{Ol}_{1} \mathrm{Ol}_{1} \mathrm{Ol}_{2} \mathrm{Ol}_{2}$ & 18.74 & $\mathrm{D}$ & & & $\mathrm{Ol}_{1} \mathrm{Ol}_{1} \mathrm{Ol}_{2} \mathrm{Ol}_{2}$ & 1.48 & $B C$ \\
\hline & & $\mathrm{Ol}_{1} \mathrm{Ol}_{1} \mathrm{Ol}_{2} \mathrm{Ol}_{2}$ & 19.14 & D & & & $\mathrm{Ol}_{1} \mathrm{Ol}_{1} \mathrm{Ol}_{2} \mathrm{Ol}_{2}$ & 1.63 & $A B$ \\
\hline & & $\mathrm{Ol}_{1} \mathrm{Ol}_{1} \mathrm{Ol}_{2} \mathrm{Ol}_{2}$ & 3.73 & $E$ & & & $\mathrm{Ol}_{1} \mathrm{Ol}_{1} \mathrm{Ol}_{2} \mathrm{Ol}_{2}$ & 1.56 & A \\
\hline
\end{tabular}

previously developed to discern the presence or absence of the gene Rma for resistance to $M$. arenaria [31,35]. Marker assisted selection (MAS) was employed to detect the progeny from Cross 25 (PI 651853 Tifguard/PI 653717 York) that were nematode resistant, as well as high oleic based on Rma and ahFAD2 genotyping. Out of $125 \mathrm{~F}_{2}$ progeny, $28(22.4 \%)$ were homozygous for the resistance allele, 46 (36.8\%) were heterozygous, and 51 (40.8\%) were homozygous for the susceptible allele. Of the 28 progeny carrying the nematode resistant allele, 11 (39\%) were also determined to be high oleic, based on ahFAD2 genotyping and gas chromatography. Chi square analysis demonstrated that this dominant trait was neither consistent with monogenic (3:1) segregation 
Table 5 Mean squares analysis of variance across three 15:1 crosses 17, 19, \& 28

\begin{tabular}{|c|c|c|c|c|c|c|c|c|c|}
\hline & Palmitic & Stearic & Oleic & Linoleic & Arachidic & Gadoleic & Behenic & Lignoceric & $\mathrm{O} / \mathrm{L}$ ratio \\
\hline Cross & $19.79^{* *}$ & $17.66^{* *}$ & $155.17^{* *}$ & $79.36^{* *}$ & $2.05^{* *}$ & $0.90^{* *}$ & $5.70^{* *}$ & $0.30+$ & $35.45^{*}$ \\
\hline Genotypes & $66.08^{* *}$ & 1.20 & $3410.13^{* *}$ & $2529.33^{* *}$ & $0.15^{*}$ & $1.50^{* *}$ & 0.60 & $0.22^{*}$ & $1191.92^{* *}$ \\
\hline A genome locus & $81.22^{* *}$ & 0.10 & $3980.22^{* *}$ & $2989.27^{* *}$ & 0.07 & $1.52^{* *}$ & 0.780 & 0.19 & $2250.85^{* *}$ \\
\hline B genome locus & $80.87^{* *}$ & 0.51 & $4273.82^{* *}$ & $3268.41^{* *}$ & 0.04 & $1.88^{* *}$ & 0.29 & 0.22 & $1887.65^{* *}$ \\
\hline$A B$ interaction & $5.27^{* *}$ & 0.89 & $485.01^{* *}$ & $372.87^{* *}$ & 0.12 & $0.25^{*}$ & 0.21 & 0.03 & $1137.08^{* *}$ \\
\hline Cross $x$ genotype & $3.34^{* *}$ & 0.66 & $99.13^{* *}$ & $67.02^{* *}$ & 0.05 & 0.12 & 0.32 & 0.10 & 12.44 \\
\hline Cross $\times$ A locus & 0.59 & 1.15 & 23.25 & 19.47 & 0.03 & $0.27^{*}$ & 0.54 & $0.27^{*}$ & 19.29 \\
\hline Cross $x$ a1 & 0.16 & 0.81 & 5.55 & 11.86 & 0.03 & $0.25+$ & 0.65 & $0.30+$ & $27.57 \dagger$ \\
\hline Cross $x$ d 1 & 1.04 & 1.56 & 38.86 & 24.97 & 0.04 & $0.25+$ & 0.52 & 0.25 & 8.51 \\
\hline Cross $\times$ B locus & $4.44^{* *}$ & 1.00 & 40.14 & $28.57 \dagger$ & 0.09 & 0.03 & 0.22 & 0.02 & $21.36+$ \\
\hline Cross $x$ a2 & $6.04^{* *}$ & 0.06 & $63.01 \dagger$ & $36.20+$ & 0.00 & 0.05 & 0.19 & 0.00 & $37.85^{*}$ \\
\hline Cross $x \mathrm{~d} 2$ & 1.40 & 1.71 & 10.38 & 12.22 & $0.17 \dagger$ & 0.03 & 0.26 & 0.04 & 11.97 \\
\hline C2 & $-0.39 \pm 0.16^{*}$ & $0.87 \pm 0.13^{* *}$ & $-1.70 \pm 0.69^{*}$ & $0.68 \pm 0.56$ & $0.30 \pm 0.04^{* *}$ & $-0.13 \pm 0.05^{* *}$ & $0.31 \pm 0.10^{* *}$ & $0.05 \pm 0.05$ & $-1.23 \pm 0.47^{* *}$ \\
\hline a1 & $-1.27 \pm 0.11^{* *}$ & $-0.04 \pm 0.09$ & $8.91 \pm 0.47^{* *}$ & $-7.68 \pm 0.39^{* *}$ & $-0.03 \pm 0.03$ & $0.15 \pm 0.03^{* *}$ & $-0.06 \pm 0.07$ & $0.01 \pm 0.03$ & $5.78 \pm 0.32^{* *}$ \\
\hline d1 & $0.29 \pm 0.17 \dagger$ & $0.04 \pm 0.14$ & $-1.91 \pm 0.70^{* *}$ & $2.00 \pm 0.57^{* *}$ & $-0.03 \pm 0.04$ & $-0.12 \pm 0.05^{*}$ & $-0.17 \pm 0.10$ & $-0.09 \pm 0.05 \dagger$ & $-4.97 \pm 0.48^{* *}$ \\
\hline a2 & $-1.28 \pm 0.11^{* *}$ & $-0.07 \pm 0.09$ & $9.38 \pm 0.47^{* *}$ & $-8.21 \pm 0.39^{* *}$ & $-0.03 \pm 0.03$ & $0.19 \pm 0.03^{* *}$ & $-0.04 \pm 0.07$ & $0.04 \pm 0.03$ & $5.85 \pm 0.32 * *$ \\
\hline $\mathrm{d} 2$ & $0.04 \pm 0.17$ & $-0.10 \pm 0.14$ & $-1.51 \pm 0.71^{*}$ & $1.38 \pm 0.58^{*}$ & $-0.01 \pm 0.04$ & $0.01 \pm 0.05$ & $0.11 \pm 0.11$ & $0.07 \pm 0.05$ & $-4.75 \pm 0.48^{* *}$ \\
\hline (aa) 12 & $-0.39 \pm 0.11^{* *}$ & $-0.06 \pm 0.09$ & $3.87 \pm 0.47^{* *}$ & $-3.43 \pm 0.39^{* *}$ & $-0.03 \pm 0.03$ & $0.09 \pm 0.03^{*}$ & $-0.05 \pm 0.07$ & $0.00 \pm 0.03$ & $5.40 \pm 0.32^{* *}$ \\
\hline (ad) 12 & $0.11 \pm 0.17$ & $-0.14 \pm 0.14$ & $-0.53 \pm 0.71$ & $0.50 \pm 0.58$ & $-0.03 \pm 0.04$ & $0.02 \pm 0.05$ & $0.01 \pm 0.11$ & $0.05 \pm 0.05$ & $-4.58 \pm 0.48^{* *}$ \\
\hline (da) 12 & $0.10 \pm 0.17$ & $-0.17 \pm 0.14$ & $-1.32 \pm 0.70+$ & $1.43 \pm 0.57^{*}$ & $-0.04 \pm 0.04$ & $-0.02 \pm 0.05$ & $-0.01 \pm 0.10$ & $0.02 \pm 0.05$ & $-4.88 \pm 0.48^{* *}$ \\
\hline (dd) 12 & $0.48 \pm 0.25 \dagger$ & $0.29 \pm 0.21$ & $-3.61 \pm 1.06^{* *}$ & $2.68 \pm 0.87^{* *}$ & $0.13 \pm 0.06^{*}$ & $-0.09 \pm 0.07$ & $0.16 \pm 0.16$ & $-0.03 \pm 0.07$ & $4.00 \pm 0.72^{* *}$ \\
\hline Error & 1.21 & 0.81 & 21.77 & 14.49 & 0.07 & 0.11 & 0.48 & 0.11 & 10.09 \\
\hline
\end{tabular}

$\mathrm{t}^{*}{ }^{*}$ ** Denote significant effects at $\mathrm{P}<0.10, \mathrm{P}<0.05$, and $\mathrm{P}<0.01$, respectively.

nor with digenic (15:1) segregation; however, these results were consistent with a 9:7 ratio. Segregation distortion was a factor, however, for this marker because the genotypic distribution did not fit a 1:2:1 ratio. There was an excess of susceptible alleles in this population. Significant segregation distortion of Rma alleles was also observed in a previous study evaluating $\mathrm{F}_{4}$ and $\mathrm{F}_{5}$ progeny [31]. This distortion could have been caused either by errors in genotyping, recombination between the SSR marker and Rma gene, distorted genotypes prior to or after fertilization, or complexity due to introgression of this trait from a diploid ancestor. Future work will include inoculating these susceptible and resistant lines to check for resistance to root galling and egg mass.

\section{Conclusion}

Development of lines with enhanced traits is often a lengthy process of breeding, selection, and phenotypic evaluation through multiple generations to obtain the desired trait stacking. This is especially true when plants have long generation times and need to mature fully or be evaluated as densely planted late-generation populations across multiple environments prior to evaluating the presence or absence of multiple traits of interest. In theory, marker-assisted selection can be utilized as an aid in the breeding process to expedite the identification of a particular genotype linked to a desired phenotype in very early stages of a plant's development. The markers utilized in this study allowed the selection of the high oleic trait, as well as, nematode resistant lines which can now be used to advance only the desirable progenies/selections in our breeding program. Analyzing the ahFAD2 genotypes and fatty acid compositions of these segregating peanut populations clearly demonstrated that the fatty acid contents are quantitative in nature although much of the variability in the predominant fatty acids (oleic, linoleic, and palmitic) is controlled by only two loci. Oleic and linoleic acids displayed five unique phenotypes based on the total number of mutant or wild type alleles in the genotype. Dominance was incomplete for $a h F A D 2$ and both homoeologous loci displayed significant additive effects. Further, the ahFAD2 loci do exhibit pleiotropic interactions for palmitic, oleic, linoleic acid contents, and the $\mathrm{O} /$ $\mathrm{L}$ ratio. Fatty acid levels in these progeny were affected by the parental genotype, suggesting that other genes influence fatty acid levels in peanut. These data demonstrate that the high oleic trait is not totally controlled by dominant gene action. 


\section{Materials and methods Plant materials}

Seeds were obtained from the USDA-ARS Plant Genetic Resources Conservation Unit in Griffin, GA. Two seeds per entry were germinated by planting them in a metal food serving tray containing a 1:1 mixture of Metro-Mix 300 (Griffin Greenhouse and Nursery Supplies, Ball Ground, GA) and perlite. Plants were watered daily using an automatic watering system and daylight was extended by turning the greenhouse lights on from 6 to $11 \mathrm{pm}$. Greenhouse conditions were set to maintain temperatures between $21^{\circ} \mathrm{C}$ and $29.5^{\circ} \mathrm{C}$. Emasculation of anthers from flowers of the female parents started about six weeks after planting. Non-emasculated flowers were removed every morning. Flowers from the male parents were selected in the morning and placed in vials with water which were placed in a refrigerator until the evening. Pollinations were performed between 6:30 and 8:00 pm. Plastic wire ties were used to mark the emasculated flowers and aid in identification of the desired pegs. $\mathrm{F}_{1}$ seeds were harvested $90 \mathrm{~d}$ after the last pollination except for in crosses with PI 565455 Chico [36] which were harvested $80 \mathrm{~d}$ after the last pollination. All harvested $F_{1}$ seeds were planted and grown in the greenhouse. Plants in the $\mathrm{F}_{1}$ generation determined to be a product of self pollination via ahFAD2 genotyping were eliminated, while the hybrids were allowed to self and produce $\mathrm{F}_{2}$ seed.

One hundred twenty five $F_{2}$ seed were randomly selected from each of the following four peanut populations: Cross 17 (PI 652938 Florida-07 A. hypogaea L. [37]/PI 280688 A. hypogaea subsp. hypogaea var. hirsuta Köhler), Cross 19 (PI 653717 York A. hypogaea L./PI 502096 A. hypogaea subsp. fastigiata Waldron var. peruviana Krapov. \& W.C. Gregory), Cross 25 (PI 651853 Tifguard A. hypogaea L. [32]/PI 653717 York A. hypogaea L.), and Cross 28 (PI 565455 Chico A. hypogaea L. [36]/PI 653717 York $A$. hypogaea L.). Two smaller populations with 18 individuals from Cross 21 (PI 652938 Florida-07 $A$. hypogaea L. [37]/PI 502096 A. hypogaea subsp. fastigiata var. peruviana) and 21 individuals from Cross 27 (PI 565455 Chico A. hypogaea L. [36]/PI 652938 Florida-07 $A$. hypogaea L. [37]) were also included in the analysis. These crosses were selected because the parents were either high oleic (York and Florida-07) or represent diverse germplasm with traits such as early maturity (Chico) or pest/ disease resistance to nematodes, leaf spots, or tomato spotted wilt virus (TSWV), all of which are significant problems for peanut production in the southeastern USA. All of the parents and 539 individual $\mathrm{F}_{2}$ seeds were evaluated by ahFAD2 SNP genotyping [23,24] and total fatty acid composition (palmitic C16:0, stearic C18:0, oleic C18:1, linoleic C18:2, arachidic C20:0, gadoleic C20:1, behenic C22:0, and lignoceric acid C24:0) was collected to assess each genotype and phenotype (Additional file 1:
Table S1). Method used to analyze total fatty acid composition is described below. Further, a total of $15 \%$ of the $\mathrm{F}_{2}$ progeny were randomly selected and the ahFAD2 genotyping was replicated to ensure accuracy. No genotyping errors were revealed in this replication.

\section{DNA extraction and PCR}

All DNA samples were extracted by following the directions from an Omega-BioTek E.Z.N.A Plant DNA kit (Norcross, GA.). Leaf tissue or slices from single seeds (75-150 mg) were used to extract DNA. Samples were placed in a $2 \mathrm{~mL}$ micro-centrifuge tube along with two 3 $\mathrm{mm}$ tungsten carbide beads (Qiagen Valencia, CA.) and $600 \mu \mathrm{l}$ of P1 buffer from the Omega-BioTek kit. Tissue was pulverized by a Retsch Mixer Mill 301 (Leeds, UK) at $30 \mathrm{~Hz}$ for three minutes. Extracts were quantified on a DyNA Quant 200 fluorometer from Hoefer Pharmacia Biotech (San Francisco, CA). In addition, all samples were loaded on a $1 \%$ agarose gel (stained with ethidium bromide) along with a Low DNA Mass ${ }^{\mathrm{TM}}$ Ladder from Invitrogen (Carlsbad, CA) to evaluate quantity and quality of each extraction. All samples were subsequently diluted to $10 \mathrm{ng} / \mu \mathrm{l}$ for Real-Time PCR.

Genotyping assays were as described previously [23,24]. Briefly, genome specific SNPs identified from sequencing wild progenitors of cultivated peanut for ahFAD2 were incorporated in the probe/primer design to preferentially select the A genome when genotyping $a h F A D 2 A$ or the $\mathrm{B}$ genome when genotyping $a h F A D 2 B$. All PCR reactions were performed in an ABI StepOne ${ }^{\mathrm{rm}}$ Real-time PCR machine using MicroAmp ${ }^{\circledR}$ fast optical 48-well plate and adhesive film seals (Applied Biosystems, Foster City, CA.). Each PCR run included non-template controls to ensure that reagents were free of contaminants. In addition, several positive controls were included in each run, such as F435 to represent the homozygous recessive mutant alleles $\left(\mathrm{ol}_{1} \mathrm{Ol}_{2}\right)$, normal oleate lines to represent the homozygous wild type dominant alleles $\left(\mathrm{Ol}_{1} \mathrm{Ol}_{2}\right)$, and hetero zygous $F_{1}$ progeny. StepOne version 2.0 (Applied Biosystems) was utilized to analyze and score genotypes among parents and progeny using the default parameters.

\section{Nematode resistance marker}

The SSR marker GM565 [originally described as pPG Sseq17E3, [38]] was employed to test $F_{2}$ progeny for nematode resistance. This marker produces a $208 \mathrm{bp}$ product in resistant lines and 195 bp product in susceptible lines $[31,35]$. The forward primer sequence was $5^{\prime}$ TTT CCT TTC AAC CCT TCG TG 3' and the reverse sequence was 5' AAT GAG ACC AGC CCA AAA TGC 3'. The primers were synthesized by MWG Operon (Huntsville, AL). The total PCR volume was $10 \mu \mathrm{l}$ and consisted of $2.55 \mu \mathrm{l}$ of $\mathrm{H}_{2} 0,1 \times$ PCR Buffer, $2.5 \mathrm{mM}$ $\mathrm{MgCl}_{2}, 0.2 \mathrm{mM}$ dNTPs, $0.15 \mu \mathrm{M}$ forward primer, $0.15 \mu \mathrm{M}$ 
reverse primer, $0.1 \mathrm{U} / \mu \mathrm{l}$ of Taq polymerase, and $0.75 \mathrm{ng} / \mu \mathrm{l}$ of diluted template DNA. The PCR buffer, polymerase, and dNTPs were all obtained from Promega (Madison, WI). Cycling conditions consisted of 1 cycle at $94^{\circ} \mathrm{C}$ for $5 \mathrm{~min}$ for the initial denaturing, 38 cycles of $94^{\circ} \mathrm{C}$ for $1 \mathrm{~min}$, $56^{\circ} \mathrm{C}$ for $30 \mathrm{sec}$, and $72^{\circ} \mathrm{C}$ for $1 \mathrm{~min}, 1$ cycle of $72^{\circ} \mathrm{C}$ for $10 \mathrm{~min}$ for final extension followed by a $4^{\circ} \mathrm{C}$ hold for temporal storage. All PCRs were performed in a GeneAmp 9700 thermocycler (Applied Biosystems Foster City, CA). The resulting products were separated on a $4 \%$ agarose gel mixed in a 1:1 ratio with a high resolving agarose (MetaPhor Cambrex Rockland, ME) to a standard molecular grade agarose and stained with ethidium bromide for visualization.

\section{Oil extraction and gas chromatography}

Fatty acid composition was determined on an Agilent 7890A (Agilent Technologies, Santa Clara, CA) gas chromatograph with a flame ionization detector (FID). Oil from a small amount ( $75 \mathrm{mg})$ of ground peanut seed was extracted in $5 \mathrm{~mL}$ of heptane and transesterified to fatty acid methyl esters (FAMEs) with $500 \mu$ lof $0.5 \mathrm{~N}$ sodium methoxide. Peak separation was performed on a DB-225 capillary column $(15 \mathrm{~m} \times 0.25 \mathrm{~mm}$ i.d. with a $0.25 \mu \mathrm{m}$ film) from Agilent Technologies. One microliter of prepared sample was injected at a 60:1 split ratio into the column maintained isothermally at $280^{\circ} \mathrm{C}$. The inlet and detector were set at $280^{\circ} \mathrm{C}$ and $300^{\circ} \mathrm{C}$, respectively. The carrier gas was helium set at a flow rate of $1 \mathrm{~mL} / \mathrm{min}$ $(38 \mathrm{~cm} / \mathrm{sec})$. Peaks were identified by comparison to a FAME standard mix RM-3 (Sigma-Aldrich, St Louis, MO). A total of eight fatty acids (palmitic, stearic, oleic, linoleic, arachidic, gadoleic, behenic, and lignoceric acid) were identified in each peanut sample.

\section{Data analysis}

GraphPad Prism version 3.0 and JMP version 9.0 were employed to statistically analyze the data and to construct graphs. Correlations were determined by employing the Pearson correlation and calculating a two-tailed $\mathrm{P}$ value with 95\% confidence intervals. One way ANOVA was utilized to test for significant differences among the mean values of oleic acid for each genotypic class. Chi-square analysis was employed to test the segregation patterns for the oleic acid trait and to test for segregation distortion. Analysis of variance was employed to determine the significance of genotypic effects. Additive and dominance contrasts were estimated across all genotypes.

\section{Additional file}

Additional file 1: Table S1. Summary of ahFAD2 genotypes detected in each population (Crosses 17, 19, 21, 25, 27 \& 28), as well as the number of individuals detected per genotype, and the mean percentage of each fatty acid detected per genotype are included. The following fatty acids were collected for each individual palmitic C16:0, stearic C18:0, oleic C18:1, linoleic C18:2, arachidic C20:0, gadoleic C20:1, behenic C22:0, and lignoceric acid C24:0. The standard deviations are also listed below.

\section{Competing interests}

The authors declare that they have no competing interests.

\section{Authors' contributions}

N.A.B. extracted DNA, performed ahFAD2 genotyping, summarized genotyping data, analyzed data, initiated design and concept of study, and drafted the manuscript. R.N.P. made all the crosses to produce $F_{1}$ and $F_{2}$ seed, initiated design and concept of study, and revised the manuscript. T.G. I. carried out the mean squares analysis, statistical analysis, and revised the manuscript. M.L.W. helped edit the manuscript and made suggestions on study design. All authors read and approved the final manuscript.

\section{Acknowledgements}

The authors would like to grateful acknowledge Mr. Brandon Tonnis and Mrs. Jessica Norris for their help with gas chromatography and DNA extraction, respectively. We would also like to thank Drs. David Bertioli and Dan Gorbet for their suggestions to improve this manuscript. This research was partially supported by the United States Agency for International Development (USAID) grant ECG-A-00-07-00001-00 to the Peanut Collaborative Research Support Program (CRSP) located at the University of Georgia (UGA). USAID is not responsible for the content of this article.

\section{Author details}

${ }^{1}$ USDA ARS Plant Germplasm Resources Conservation Unit, 1109 Experiment Street, Griffin, GA 30223, USA. ²Department of Crop Science, North Carolina State University, Box 7629, Raleigh, NC 27695-7629, USA.

Received: 7 November 2012 Accepted: 28 June 2013

Published: 17 July 2013

\section{References}

1. Kris-Etherton PM, Hu FB, Ros E, Sabate J: The role of tree nuts and peanuts in the prevention of coronary heart disease: multiple potential mechanisms. J Nutr 2008, 138(9):1746S-1751S.

2. Griel AE, Eissenstat B, Juturu V, Hsieh G, Kris-Etherton PM: Improved diet quality with peanut consumption. J Am Coll Nutr 2004, 23(6):660-668.

3. Sabate J, Ang Y: Nuts and health outcomes: new epidemiologic evidence. Am J Clin Nutr 2009, 89(5):1643S-1648S.

4. Dean LL, Henrix KW, Holbrook CC, Sanders TH: Content of some nutrients in the core of the core of the peanut germplasm collection. Peanut SCi 2009, 36:104-120.

5. Teres S, Barcelo-Coblijn G, Benet M, Alvarez R, Bressani R, Halver JE, Escriba PV: Oleic acid content is responsible for the reduction in blood pressure induced by olive oil. Proc Natl Acad Sci USA 2008, 105 (37):13811-13816.

6. Pelkman $\mathrm{CL}$, Fishell VK, Maddox DH, Pearson TA, Mauger DT, Kris-Etherton PM: Effects of moderate-fat (from monounsaturated fat) and low-fat weight-loss diets on the serum lipid profile in overweight and obese men and women. Am J Clin Nutr 2004, 79(2):204-212.

7. Parthasarathy S, Khoo JC, Miller E, Barnett J, Witztum JL, Steinberg D: Low density lipoprotein rich in oleic acid is protected against oxidative modification: Implications for dietary prevention of atherosclerosis. Proc Natl Acad Sci USA 1990, 87:3894-3898.

8. Nestel P, Noakes M, Belling B, Mcarthur R, Clifton P, Janus E, Abbey M: Plasma-Lipoprotein Lipid and Lp[a] Changes with Substitution of Elaidic Acid for Oleic-Acid in the Diet. J Lipid Res 1992, 33(7):1029-1036.

9. Vassiliou EK, Gonzalez A, Garcia C, Tadros JH, Chakraborty G, Toney JH: Oleic acid and peanut oil high in oleic acid reverse the inhibitory effect of insulin production of the inflammatory cytokine TNF-alpha both in vitro and in vivo systems. Lipids Health Dis 2009, 8:25.

10. Yu S, Pan L, Yang Q, Min P, Ren Z, Zhang H: Comparison of the Delta(12) fatty acid desaturase gene between high-oleic and normal-oleic peanut genotypes. J Genet Genomics 2008, 35(11):679-685. 
11. Andersen PC, Gorbet DW: Influence of year and planting date on fatty acid chemistry of high oleic acid and normal peanut genotypes. J Agric Food Chem 2002, 50(5):1298-1305.

12. Moore KM, Knauft DA: The inheritance of high oleic acid in peanut. $J$ Hered 1989, 80:252-253.

13. Jung S, Swift D, Sengoku E, Patel M, Teule F, Powell G, Moore K, Abbott A: The high oleate trait in the cultivated peanut [Arachis hypogaea L.]. I. Isolation and characterization of two genes encoding microsomal oleoyl-PC desaturases. Mol Genet Genomics 2000, 263(5):796-805.

14. Cohn JS: Oxidized fat in the diet, postprandial lipaemia and cardiovascular disease. Curr Opin Lipidol 2002, 13(1):19-24.

15. Norden AJ, Gorbet DW, Knauft DA, Young CT: Variability in oil quality among peanut genotypes in the Florida breeding program. Peanut $\mathrm{SC}$ 1987, 14:7-11.

16. Jung S, Powell G, Moore K, Abbott A: The high oleate trait in the cultivated peanut [Arachis hypogaea L]. II. Molecular basis and genetics of the trait. Mol Genet Genomics 2000, 263(5):806-811.

17. López Y, Nadaf HL, Smith OD, Connell JP, Reddy AS, Fritz AK: Isolation and characterization of the Delta(12)-fatty acid desaturase in peanut (Arachis hypogaea L.) and search for polymorphisms for the high oleate trait in Spanish market-type lines. Theor App/ Genet 2000, 101(7):1131-1138.

18. Ray TK, Holly SP, Knauft DA, Abbott AG, Powell GL: The primary defect in developing seed from the high oleate variety of peanut (Arachis hypogaea L.) is the absence of delta 12-desaturase activity. Plant Sci 1993, 91:15-21.

19. Schwartzbeck JL, Jung S, Abbott AG, Mosley E, Lewis S, Pries GL, Powell GL: Endoplasmic oleoyl-PC desaturase references the second double bond. Phytochemistry 2001, 57(5):643-652.

20. Bruner $A C$, Jung $S$, Abbott $A G$, Powell $G L$ : The naturally occurring high oleate oil character in some peanut varieties results from reduced oleoyl-pc desaturase activity from mutation of aspartate 150 to asparagine. Crop Sci 2001, 41:522-526.

21. López Y, Smith OD, Senseman SA, Rooney WL: Genetic factors influencing high oleic acid content in Spanish market-type peanut cultivars. Crop Sci 2001, 41(1):51-56.

22. Chu Y, Ramos L, Holbrook CC, Ozias-Akins P: Frequency of a loss-of-function mutation in oleoyl-PC desaturase (ahFAD2A) in the mini-core of the US peanut germplasm collection. Crop Sci 2007, 47(6):2372-2378.

23. Barkley NA, Chamberlin Chenault KD, Wang ML, Pittman RN: Development of a real-time PCR genotyping assay to identify high oleic acid peanuts (Arachis hypogaea L.). Mol Breed 2010, 25:541-548.

24. Barkley NA, Wang ML, Pittman RN: A real-time PCR genotyping assay to detect FAD2A SNPs in peanuts (Arachis hypogaea L.). Electron J Biotechnol 2011. doi:10.2225/vol14-issue1-fulltext-12.

25. Isleib TG, Wilson RF, Novitzky WP: Partial dominance, pleiotropism, and epistasis in the inheritance of the high oleate trait in peanut. Crop Sci 2006, 46:1331-1335.

26. Barkley NA, Chamberlin Chenault KD, Wang ML, Pittman RN: Genotyping and fatty acid composition analysis in segregating peanut (Arachis hypogaea L.) populations. Peanut Sci 2011, 38(1):11-19.

27. Isleib TG, Young CT, Knauft DA: Fatty acid genotypes of five Virginia-type peanut cultivars. Crop Sci 1996, 36:556-558.

28. Zhu C, Zhang YM: An EM algorithm for mapping segregation distortion loci. BMC Genet 2007, 8:82.

29. Hong Y, Chen X, Liang X, Liu H, Zhou G, Li S, Wen S, Holbrook CC, Guo B: A SSR-based composite genetic linkage map for the cultivated peanut (Arachis hypogaea L.) genome. BMC Plant Biol 2010, 10:17.

30. Varshney RK, Bertioli DJ, Moretzsohn MC, Vadez V, Krishnamurthy L, Aruna R, Nigam SN, Moss BJ, Seetha K, Ravi K, et al: The first SSR-based genetic linkage map for cultivated groundnut (Arachis hypogaea L.). Theor Appl Genet 2009, 118(4):729-739.

31. Nagy ED, Chu Y, Guo Y, Khanal S, Tang S, Li Y, Dong W, Timper P, Tayler C, Ozias-Akins $P$, et al: Recombination is suppressed in an alien introgression on chromosome $5 \mathrm{~A}$ of peanut harboring $\mathrm{Rma}$, a dominant root knot nematode resistant gene. Mol Breed 2010, 26:357-370.

32. Holbrook CC, Timper P, Culbreath AK, Kvien CK: Registration of 'Tifguard' peanut. J Plant Reg 2008, 2(2):92-94.

33. Gorbet DW, Shokes FM: Registration of 'C-99R' peanut. Crop Sci 2002 , 42:2207.

34. Simpson CE, Starr JL: Registration of 'COAN' peanut. Crop Sci 2001, 41:918.
35. Chu Y, Wu CL, Holbrook CC, Tillman BL, Person G, Ozias-Akins P: Marker assisted selection to pyramid nematode resistance and the high oleic trait in peanut. Plant Genome 2011, 4(2):110-117.

36. Bailey WK, Hammons RO: Registration of Chico peanut germplasm (Reg. No. GP 2). Crop Sci 1975, 15(1):105

37. Gorbet DW, Tillman BL: Registration of 'Florida-07' peanut. J Plant Reg 2009, 3(1):14-18.

38. Ferguson ME, Burow MD, Schulze SR, Bramel PJ, Paterson AH, Kresovich S, Mitchell S: Microsatellite identification and characterization in peanut (A-hypogaea L.). Theor App/ Genet 2004, 108(6):1064-1070.

doi:10.1186/1471-2156-14-62

Cite this article as: Barkley et al:: Genotypic effect of ahFAD2 on fatty acid profiles in six segregating peanut (Arachis hypogaea $\mathrm{L}$ ) populations. BMC Genetics 2013 14:62

\section{Submit your next manuscript to BioMed Central and take full advantage of:}

- Convenient online submission

- Thorough peer review

- No space constraints or color figure charges

- Immediate publication on acceptance

- Inclusion in PubMed, CAS, Scopus and Google Scholar

- Research which is freely available for redistribution 